\title{
Pneumomediastinum, pneumoperitoneum, and pneumoretroperitoneum secondary to afferent loop perforation after upper endoscopy in patient with Billroth II gastrectomy
}

\author{
Hao-Ai Hou*1, Szu-Ying Chen ${ }^{2}$, Chi-Min Shih ${ }^{3}$ \\ ${ }^{1}$ Division of Gastroenterology, Department of Internal Medicine, Chia-Yi Hospital, Ministry of Health and Welfare, Taiwan, ROC \\ ${ }^{2}$ Department of Radiology, Chia-Yi Hospital, Ministry of Health and Welfare, Taiwan, ROC \\ ${ }^{3}$ Department of Pathology, Chia-Yi Hospital, Ministry of Health and Welfare, Taiwan, ROC
}

Received: January 8, 2016

DOI: $10.5430 /$ crim.v3n1p71
Accepted: February 15, $2016 \quad$ Online Published: February 19, 2016

URL: http://dx.doi.org/10.5430/crim.v3n1p71

\begin{abstract}
Complications related by upper endoscopy include bleeding, perforation and infections but they are rare on simply diagnostic endoscopy. Duodenal perforation is less common but mortality rates are high. Diagnosis is based on keeping high suspicion that makes early detection to offer optimal treatments and better outcomes. Surgical intervention is standard treatment but some cases could benefit from conservative care. However, there was little literature description of afferent loop perforation after upper endoscopy. Herein, we report a case of pneumomediastinum, pneumoperitoneum, and pneumoretroperitoneum secondary to afferent loop perforation after upper endoscopy in patient with Billroth II gastrectomy. This rare case should be the reminder for physicians carefully performing upper endoscopy in patients with Billroth-II gastrectomy and keeping high suspicion of perforation after endoscopy if abdominal pain.
\end{abstract}

Key Words: Pneumomediastinum, Pneumoperitoneum, Penumoretroperitoneum, Afferent loop perforation, Billroth II gastrectomy

\section{INTRODUCTION}

Esophagogastroduodenoscopy (upper endoscopy) could visualize from oropharynx, esophagus, stomach to the proximal duodenum under real-time assessment and even intervention. It has already been an essential part of gastrointestinal practice for upper gastrointestinal disease. Complications related by upper endoscopy include bleeding, perforation and infections but they are rare on simply diagnostic endoscopy. Among these complications, duodenal perforation is a more rare but potentially serious complication of upper gastrointestinal endoscopy. The standard management is surgical repair but some case series show successfully settled with nonsurgical management. The most case reports are duodenal perforation related by complicated endoscopic retrograde cholangiopancreatography with or without intervention. To our knowledge, there was no literature description of afferent loop perforation after diagnostic upper endoscopy. Herein, we presented a case of pneumomediastinum, pneumoperi-

\footnotetext{
*Correspondence: Hao-Ai Hou; Email: oldfatfg@gmail.com; Address: Division of Gastroenterology, Department of Internal Medicine, Chia-Yi Hospital, Ministry of Health and Welfare, Taiwan, ROC.
} 
toneum, and pneumoretroperitoneum secondary to afferent loop perforation after upper endoscopy in patient with Billroth II gastrectomy.

\section{Case presentation}

An 80-year-old woman with medical histories of peptic ulcer post subtotal gastrectomy with Billroth-II anastomosis three decades ago and old pulmonary tuberculosis post complete medical treatments two decades ago presented to out outpatient department with progressive anorexia, rapid body weight loss and intermittent right upper quadrant tenderness in one year. She didn't regularly follow-up upper gastrointestinal condition after gastrectomy. No previous oral radiation history, complicated dental problems, neurologic deficits, hypogeusia, upper gastrointestinal bleeding, postprandial satiety, chronic infection disease, severe cardiopulmonary problems or any drugs related anorexia was mentioned. She also denied any anxiety or depression. Initial vital signs were stable (blood pressure: 102/57 mmHg, heart rate: 68 beats per minute, respiratory rate: 16 counts per minute and body temperature: $36.3^{\circ} \mathrm{C}$ ). Complete blood cell (CBC) counts showed white blood cell count at $5,600 / \mu 1$, hemoglobin level at $7.5 \mathrm{~g} / \mathrm{dl}$ and the platelet count at $286,000 / \mu \mathrm{l}$. Mean corpuscular volume was $90.3 \mathrm{fl}$ and reticulocyte index was $2.0 \%$. Her renal function and liver function tests were all within the normal range, including creatinine at $0.8 \mathrm{mg} / \mathrm{dl}$, GOT at 18 IU/L, GPT at $7 \mathrm{IU} / \mathrm{L}$, and total bilirubin at $0.2 \mathrm{mg} / \mathrm{dl}$, except hypoalbuminemia at $3.04 \mathrm{~g} / \mathrm{dl}$. The abdominal ultrasound done for right upper quadrant tenderness disclosed bilateral intrahepatic and common bile duct dilatation without gallstone or common bile duct stone. Therefore she was hospitalized for further surveys. Subsequent abdominal computed tomography $(\mathrm{CT})$ revealed one $4.4 \mathrm{~cm} \times 2.4 \mathrm{~cm} \times 3.4 \mathrm{~cm}$ soft tissue tumor of the ampulla of Vater (see Figure 1) causing upstream intra- and extra-hepatic bile ducts, main pancreatic duct dilation and gallbladder distention. Multiple soft tissue nodules in the visible lungs were also shown and metastasis could not be ruled out. We performed upper endoscopy for further examining this soft tissue tumor. Ampullary tumor with nodulation and ulceration complicated with partial obstruction at afferent loop could be visualized (see Figure 2). Biopsy for total eight pieces to confirm malignancy was done and its final pathology report is adenocarcinoma (see Figure 3). However, abdomen pain was complained on the next day. Her heart rate increased to around 110 beats per minute. No fever was shown but her blood pressure was lower than baseline. Physical examinations revealed diffuse abdominal tenderness with equivocal peritoneal sign and muscle guarding. The following plain film showed pneumoperitoneum, pneumomediastinum and pneumoretroperitonium with pos- itive falciform ligament sign, double wall sign and hepatic edge sign (see Figure 4a). Repeated CT confirmed bowel perforation and favored air-leak from afferent loop where tumor located (see Figure 4b). Because patient refused any surgical intervention, we made her bowel rest and administered prophylactic broad spectrum antibiotics as Meropenem $1 \mathrm{~g}$ $\mathrm{Q} 8 \mathrm{H}$. Then she was transferred to the Intensive Care Unit for further care. Subsequent leukocytosis (WBC at 14,130/ $\mu \mathrm{l}$ ) with elevated C-reactive protein (CRP at $13.9 \mathrm{mg} / \mathrm{dl}$ ) was shown and hypotension developed. Short-course vasopressor was administered. Total parenteral nutrition was also administered for predictable long-time nothing per oral. Following KUB on day 6 showed almost resolution of free air (see Figure 5). Oral intake initiated since day 8 of afferent loop perforation and she could tolerate well with no residual abdominal pain. Unfortunately, this case suffered from hospital acquired pneumonia complicated with acute respiratory distress syndrome and finally died from severe respiratory failure.

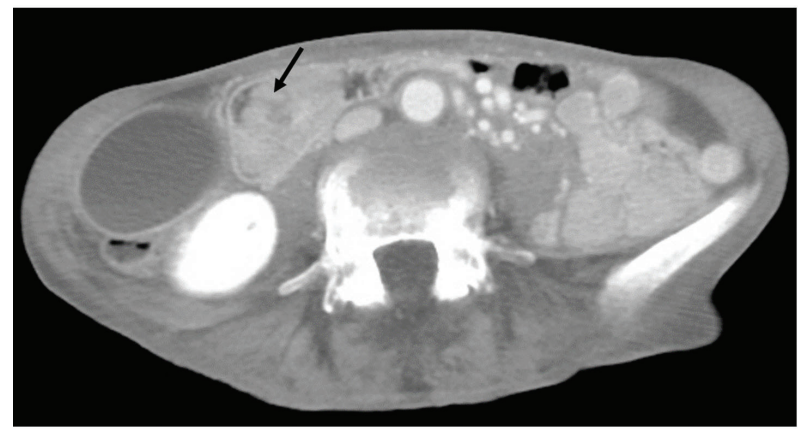

Figure 1. One soft tissue tumor of the ampulla of Vater (see arrow)

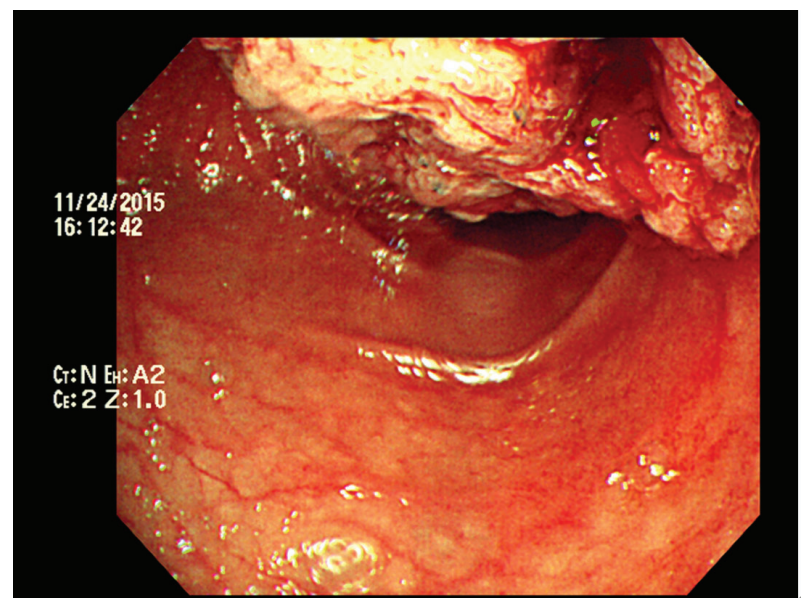

Figure 2. One ampullary mass with partial obstruction at afferent loop and spontaneously bleeding under endoscopy 


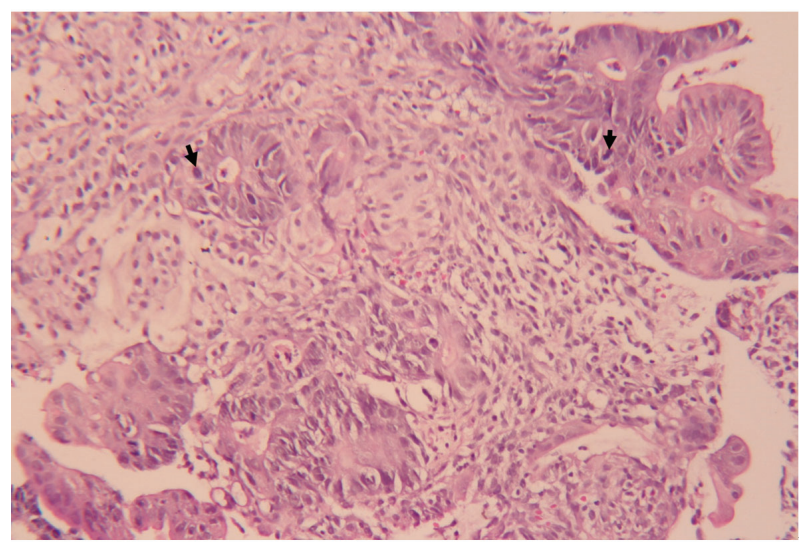

Figure 3. (HE, ×200). Neoplastic microglands with adjacent desmoplastic stromal reaction was demonstrated. Mitosis was also shown (see arrow)


Figure 4. a: Pneumomediastinum, pneumoperitoneum, and pneumoretroperitoneum were demonatrated (day 1); b: After 5 days (day 6), free air almost resolved

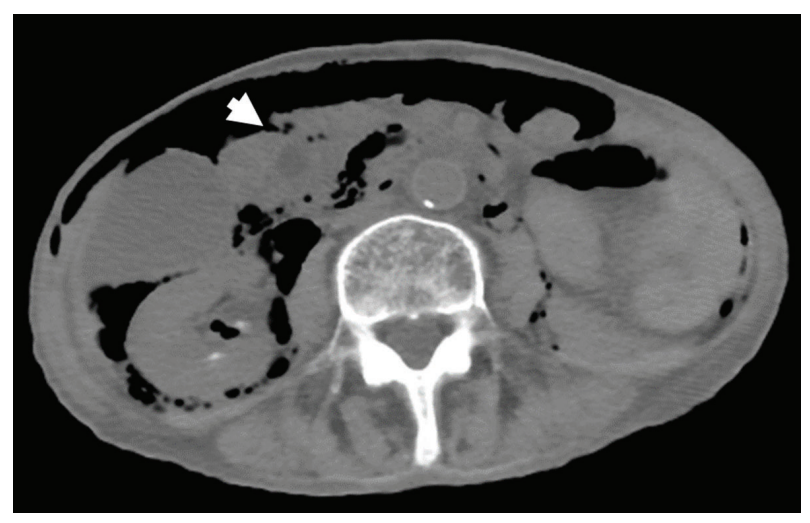

Figure 5. Predominant air over right retroperitoneum and highly suspected air leak from afferent loop where ampullary mass located (see arrow)

\section{Discussion}

Upper endoscopy has already been a common clinical practice for upper gastrointestinal disease. Complications related by upper endoscopy include bleeding, perforation and infections. Older study in 1974 by American Society for Gastrointestinal Endoscopy Survey showed the overall complication rate was $0.13 \% .^{[1]}$ Recent study report of overall complications rate by Mayo Clinic College of Medicine shows decreased overall complications rate as 0.0002 percent for simple diagnostic upper endoscopy. ${ }^{[2]}$ For perforations, esophageal perforation is the most common site of perforation during the upper endoscopy. Duodenal perforation is a more rare but potentially serious complication of upper gastrointestinal endoscopy. The endoscopy related duodenal perforation was mostly on diagnostic and therapeutic endoscopic retrograde cholangiopancreatography. Its incidence was around $0.6 \%$ of procedures. ${ }^{[3]}$ Only one retrospective case series reported duodenum perforation rate during upper endoscopy is $0.033 \% .{ }^{[4]}$ Abnormal anatomy (ex: Billroth II gastrectomy) is one of risk factors for perforation. However rare reports showed the incidence of bowel loop perforation by forward view endoscopy on patients with B-II gastrectomy. Although the incidence of duodenal perforations by upper endoscopy is low, duodenal perforation related mortality has been reported high as $28 \% .{ }^{[4]}$ In cases who failed by conservative management, mortality increased up to $50 \% .^{[5]}$ The major cause of mortality is sepsis secondary to peritonitis. Duodenal perforation presenting with predominant retroperitoneal air that tracked to mediastinum and peritoneum was seen in our case. Some hypotheses suggest duodenal wall traumas make insufflated air enter the mucosa and the mediastinum. ${ }^{[6]}$ To be high suspicion is important to diagnose endoscopy-related perforation and early diagnosis is associated with better outcomes under high successful rate of nonsurgical treatments. Perforation should be taken into account in any case with acute developed abdominal symptoms after upper endoscopy. However the clinical presentations of patients with perforation after upper endoscopy are usually nonspecific. One study reported only $64 \%$ had mild to moderate abdominal tenderness and only $18 \%$ had peritoneal signs. ${ }^{[7]}$ The diagnostic images include abdominal X-ray, CT and upper GI series. The abdominal X-ray could demonstrate free air outlining the liver, kidney, psoas muscle and even bowel wall. Abdominal CT scans usually confirm the diagnosis of perforation but the amount of air does not correlate with the severity of the disease. Upper GI series could diagnosis perforation by contrast extravasation but that have poor sensitivity for microperforation. Even if all above negative image studies, up to $10 \%$ cases of perforation could not be detected. ${ }^{[8]}$ According to 2014 European Society of Gastrointestinal Endoscopy (ESGE) guideline for managements of iatrogenic endoscopic perforations, ${ }^{[9]}$ treating endoscopy related duodenal perforation depends on recognition time (instant or delayed $>24$ hour), whether pos- 
sible endoscopic closure after immediate recognition, and any extravasation on CT finding. But the evidences are almost coming from ERCP related duodenal perforation. Little evidence directs on the upper endoscopy related afferent loop perforation on patients with B-II gastrectomy. Traditionally clinical findings include peritoneal signs and sepsis indicated the necessary of surgical intervention. Otherwise, the patient may be closely monitored with bowel rest, fluid hydration, and broad-spectrum antibiotics administration. Serial abdominal exams and images should be followed. Once clinical improvement, patient could try oral diet and advance slowly.
In conclusion, we presented a case of pneumomediastinum, pneumoperitoneum, and pneumoretroperitoneum secondary to afferent loop perforation after upper endoscopy in patient with Billroth II gastrectomy. This rare case reminds physicians that for patients with B-II gastrectomy have risks of afferent loop perforation due to anatomy alternation, much air insufflation, biopsy procedure or friability of bowel wall. Besides, duodenum perforation should be kept in mind when acute abdominal discomforts develop after upper endoscopy. Nonsurgical treatments are alternative managements but clinical conditions should be closely monitored in these rare cases.

\section{REFERENCES}

[1] Silvis SE, Nebel O, Rogers G, et al. Endoscopic complications. Results of the 1974 American Society for Gastrointestinal Endoscopy Survey. Jama. 1976; 235(9): 928-30. PMid:128642 http: //dx.doi.org/10.1001/jama.1976.03260350032023

[2] Wolfsen HC, Hemminger LL, Achem SR, et al. Complications of endoscopy of the upper gastrointestinal tract: a single-center experience. Mayo Clinic proceedings. 2004; 79(10): 1264-7. PMid:15473407 http://dx.doi.org/10.4065/79.10.1264

[3] Andriulli A, Loperfido S, Napolitano G, et al. Incidence rates of post-ERCP complications: a systematic survey of prospective studies. The American journal of gastroenterology. 2007; 102(8): 17818. PMid:17509029 http://dx.doi.org/10.1111/j.1572-024 1.2007.01279.x

[4] Merchea A, Cullinane DC, Sawyer MD, et al. Esophagogastroduodenoscopy-associated gastrointestinal perforations: a singlecenter experience. Surgery. 2010; 148(4): 876-80. PMid:20708766 http://dx.doi.org/10.1016/j.surg.2010.07.010

[5] Stapfer M, Selby RR, Stain SC, et al. Management of duodenal perforation after endoscopic retrograde cholangiopancreatog- raphy and sphincterotomy. Annals of surgery. 2000; 232(2): 191 PMid:10903596 http://dx.doi.org/10.1097/00000658-200 008000-00007

[6] Ciaccia D, Branch MS, Baillie J. Pneumomediastinum after endoscopic sphincterotomy. The American journal of gastroenterology. 1995; 90(3): 475-7. PMid:7872289

[7] Assalia A, Suissa A, Ilivitzki A, et al. Validity of clinical criteria in the management of endoscopic retrograde cholangiopancreatographyrelated duodenal perforations. Archives of Surgery. 2007; 142(11): 1059-64. PMid:18025334 http://dx.doi.org/10.1001/archs urg. 142.11.1059

[8] Alexiou K, Sakellaridis T, Sikalias N, et al. Subcutaneous emphysema, pneumomediastinum and pneumoperitoneum after unsuccessful ERCP: a case report. Cases J. 2009; 2(1): 120. PMid:19192290 http://dx.doi.org/10.1186/1757-1626-2-120

[9] Paspatis GA, Dumonceau JM, Barthet M, et al. Diagnosis and management of iatrogenic endoscopic perforations: European Society of Gastrointestinal Endoscopy (ESGE) Position Statement. Endoscopy. 2014; 46(8): 693-711. PMid:25046348 http://dx.doi.org/10. $1055 / s-0034-1377531$ 